\title{
Developmental Psychopathology, Positive Psychology, and Knowledge Development in Child and Youth Care: Editorial Hopes and Aspirations for the Forum
}

\author{
Carl F. Weems
}

Published online: 22 January 2009

(C) Springer Science+Business Media, LLC 2009

\section{Introduction}

This article introduces a new editorial term and outlines some of the publishing goals for the Child and Youth Care Forum. The commentary explores avenues for cultivating knowledge development in child care and intervention research by drawing from the conceptual success of the developmental psychopathology perspective and goals of the positive psychology movement thereby delineating some of the new editor's hopes and aspirations for the Forum.

It is with great pleasure that I write this commentary to open my term as editor of the Child and Youth Care Forum (CYCF). My primary goal as editor is to continue the excellent stewardship that the journal has benefited from since its inception in 1971 with founding editor Jerome Beker (as the Child Care Quarterly, see Beker 1971) and to specifically carry on the publishing initiatives begun by my most recent predecessor Dr. Marc Atkins (a focus on publishing of high quality empirical papers in child services). My hope is that CYCF remain an international, interdisciplinary outlet for publishing high quality empirical papers and theoretical reviews that have implications for child and adolescent intervention and services broadly defined, but to also expand the content. In particular, I would like to encourage the submission of papers that address both typical and atypical development as well as that address assessment issues, interventions, and services for children, adolescents, their families and other caretakers from researchers across the diverse fields that study the child/adolescent and the child/adolescent's developmental context (e.g., family, school, cultural context).

Including research from developmental psychology, clinical child and adolescent psychology, anthropology, medicine, pediatrics, pediatric psychology, psychiatry, public policy, school/educational psychology, social work, and sociology is what makes the Forum an important and unique source of knowledge for science and practice. While I hope that those already familiar with the Forum continue to submit their work and consider it a primary outlet. I also hope others from the fields noted above will find a new home to 
publish their research on youth. To this end, I discuss in the remainder of this article some avenues for cultivating knowledge development in child and adolescent care and intervention research by drawing from the conceptual success of the developmental psychopathology perspective and goals of the positive psychology movement.

The developmental psychopathology perspective has emphasized the use of developmental principles in understanding the origins and maintenance of various maladaptive behaviors and maladaptive behavior clusters (e.g., depression, panic disorder). Developmental psychopathology has been defined as "the study of the origins and course of individual patterns of behavioral maladaption" (Stroufe and Rutter 1984, p. 18). Although similar in its aims and goals, distinctions between developmental psychopathology and abnormal or clinical psychology have been emphasized in theoretical discussions to differentiate the respective fields (see Cicchetti 1984; Stroufe and Rutter 1984). Yet, as Cicchetti (1993) has noted of developmental psychopathology's distinctiveness "It is this very integration (i.e., of developmental psychology, clinical psychology, psychiatry, etc.) that sets it (developmental psychopathology) apart as a unique approach" (p. 475, text in brackets added). I would suggest that at its very core, knowledge development in child and adolescent care would similarly benefit from efforts to systematically integrate knowledge for "child actualization".

Like the developmental psychopathology perspective, the field of child and youth care ultimately encompasses diverse domains of knowledge. The goal in child and adolescent care is not simply to remediate problems (e.g., clinical psychology psychiatry), understand emotional and behavioral problems (e.g., abnormal psychology), inform the practice of community interventions (e.g., social work), or understand normal functioning (e.g., developmental psychology). The goal is the utilization of these knowledge bases (and other knowledge bases from sociology, anthropology, medicine, etc.) to foster what is best for the child and adolescent's development and functioning. In other words, to help the child and adolescent actualize (Maslow 1971) and attain their fullest potential. With this goal of actualizing child and youth development, the domains of the various fields noted above are assumed. I therefore see an important avenue for knowledge development in child and adolescent care in the intertwining of both developmental psychopathology and positive psychology (Seligman and Csikszentmihalyi 2000). In other words, in addition to fixing problems, child care must also build upon the best things in life, build upon strengths, and foster emotional, intellectual, and behavioral growth.

Another important avenue is highlighted by the developmental psychopathology perspective's recognition that pathology is multifaceted in its etiology and that particular risk factors may result in a variety of outcomes (Cicchetti 1993; Kazdin and Kagan 1994). This conceptual frame is exemplified by the concepts of equifinality and multifinality. Equifinality involves the notion that the same end state may be reached from different initial conditions and through different processes. Multifinality involves the notion that a particular risk factor may not necessarily lead to the same outcome in every individual. These notions have methodological and theoretical implications for child care research. In particular, effective child care and intervention is also multifaceted and particular practices may result in a variety of outcomes depending on context and child/family characteristics. Moreover, a positive outcome may be reached from a variety of different interventions (see e.g., Silverman et al. 1999).

While we will emphasize empirical science, one of my aspirations for the Forum is fostering the recognition that the people involved in child and adolescent care bring a diverse set of world views and most importantly that these diverse views may form complementary modes of understanding and not opposing modes (Weems 1999). For 
example, effective intervention and child care may utilize an organismic structure-function conceptual framework to understand cognitive development (e.g., Piaget 1983) but utilize an antecedent-consequence conceptual framework such as an operant conditioning (e.g., Skinner 1953) procedure to shape appropriate behavior in a classroom with these same children in an effort to facilitate classroom learning.

Drawing from both developmental psychopathology and positive psychology, fostering and understanding resilience is also an important area I would like to emphasize. Conceptually, resilience has been defined by Sroufe (1997) in a clear and useful manner which emphasizes the subtlety with which the concept must be considered. He states, "Resilience simply refers to the fact that some children facing adversity none-the-less do well (or return to positive functioning following a period of maladaption)" (p. 256). Resilience then is defined by exposure to some risk (e.g., facing adversity). Risk can be defined as "characteristics of the person or the environment that are associated with the increased probability of maladaptive developmental outcomes" (Compas et al. 1995, p. 273). Thus, papers that explore how youth over come adversity (e.g., traumatic stress, community violence) or build resilience are particularly encouraged.

In summary, I hope to emphasize in the Forum that child and youth care crosses the life stage from infancy to late adolescence and that the family and parents (Kormacher et al. 2008) and multiple contexts (Fischer et al. 2008) are involved and so we will welcome studies that employ these diverse samples. I hope to see papers that use ethnically and culturally diverse samples and aspire to publish important theoretical syntheses that integrate knowledge across domains. I hope to see papers that address strategies for helping youth overcome difficulties (e.g., mental health problems), overcome adversity (e.g., traumatic stress, community violence) or build resilience as well as papers that attempt to help normal youth actualize their potential (e.g., positive psychology goals). I hope to see methodological and assessment related papers. Indeed a broad array of research designs is important to the Forum. We will publish randomized controlled studies, open trials, quasiexperimental designs, survey studies, longitudinal designs, experimental designs, qualitative research, proof of concept, and single subject designs. Finally, I welcome incisive topical commentaries on the field and related disciplines as well as comments on articles published. Please contact me if you have ideas for a special issue or commentary.

Carl Weems

Editor in Chief, Child and Youth Care Forum

\section{References}

Beker, J. (1971). A new journal for an emerging profession. Child Care Quarterly, 1, 5-6.

Cicchetti, D. (1984). The emergence of developmental psychopathology. Child Development, 55, 1-7.

Cicchetti, D. (1993). Developmental psychopathology: Reactions, reflections, projections. Developmental Review, 13, 471-502.

Compas, B. E., Hinden, B. R., \& Gerhardt, C. A. (1995). Adolescent development: Pathways and processes of risk and resilience. Annual Review of Psychology, 46, 265-293.

Fischer, R. L., Nelson, L., Mikelbank, K., \& Coulton, C. (2008). Space to learn and grow: Assessing the capacity of a regional early care and education system. Child and Youth Care Forum, 37, 75-86.

Kazdin, A. E., \& Kagan, J. (1994). Models of dysfunction in developmental psychopathology. Clinical Psychology: Science and Practice, 1, 35-52.

Kormacher, J., Green, B., Staerkel, F., Peterson, C., Cook, G., Roggman, L., et al. (2008). Parent involvement in early childhood home visiting. Child and Youth Care Forum Volume, 37, 171-196.

Maslow, A. (1971). The farthest reaches of human nature. New York: Viking. 
Piaget, J. (1983). Piaget's theory. In W. Kessen (Ed.), Handbook of child psychology. vol. 1: History, theory, and methods. 4th ed. (pp. 103-128) P.H. Mussen (series Ed.). New York: John Wiley.

Seligman, M., \& Csikszentmihalyi, M. (2000). Positive psychology: An introduction. American Psychologist, 55, 5-14.

Silverman, W. K., Kurtines, W. M., Ginsburg, G. S., Weems, C. F., Rabian, B., \& Serafini, L. T. (1999). Contingency management, self-control, and education support in the treatment of childhood phobic disorders: A randomized clinical trial. Journal of Consulting and Clinical Psychology, 67, 675-687.

Skinner, B. F. (1953). Science and human behavior. New York: Macmillan.

Sroufe, L. A. (1997). Psychopathology as an outcome of development. Development and Psychopathology, 9, 251-268.

Stroufe, L. A., \& Rutter, M. (1984). The domain of developmental psychopathology. Child Development, $55,17-29$.

Weems, C. F. (1999). Psychological inquiry and the role of world views. Behavior and Philosophy, 27, 147-163. 